\title{
The Investigation on Physical Activity Requirement of College Students in Jiangxi Province
}

\author{
Wusi Yan \\ Pingxiang University, Jiangxi 337055, China \\ yanwusi@163.com
}

Key words: college students; sports fitness; demand; survey

\begin{abstract}
: with the rapid development of science and technology, the demand of college students is becoming more and more diversified. Types of college students as an important reserve force of national construction, only the health of college students to adapt to the social demand for talent, therefore, should be based on a comprehensive grasp of the current college students physical fitness requirements, puts forward reasonable countermeasures and suggestions, to guide college students to establish a good fitness needs.
\end{abstract}

\section{Research purposes}

Physical fitness activities will not only enable students to improve health, enhance physical fitness. Improve motor skills. But students develop intelligence, edify sentiment, exercise the will, an important measure of cultivating the modern competition consciousness and lifelong health consciousness of college students. The growing demand for sports, the current situation and development trend of their sports demand is a key problem for scholars to sports the research, such as how to correctly guide the students' physical needs, but also in the future to engage in the field of sports scholars.

\section{Research objects and methods}

\subsection{Research objects}

In this paper, Pingxiang college students conducted a questionnaire survey, a total of 1000 questionnaires were issued, of which 496 boys, 494 girls, 990 recovery, the recovery rate was 990 , the effective questionnaire was $99 \%$, the effective rate was $100 \%$.

\subsection{Research methods}

\subsubsection{Literature data method}

Through the Internet access to relevant literature books, the relevant state documents, to provide the theoretical basis for this study.

2.2.2 Questionnaire survey method

Pingxiang college students conducted a questionnaire survey, mainly to investigate the status quo of their participation in sports fitness.

2.2.3 Mathematical statistics method

Use of the SPSS13.0 software for all survey data statistics and finishing.

\section{Research results and analysis}

\subsection{Investigation and analysis of students' sports interest}

"Interest is the best teacher", once the person for something interested, they will actively take the initiative to learn, explore, practice, and produce a pleasant mood and experience in the process. It is seen from table 1 can be very interested in sports, not a lot of students, boys accounted for only $24 \%$, while the girls only $14 \%$. according to the survey, only very love sports students can actively participate in physical exercise in spare time, most of the students take interest in sports is generally not essential. Those who do not love, love sports students in their spare time to rest in the dormitory to participate in physical exercise. 
Table 1 students to participate in sports fitness interest in Statistics (496 boys, 494 girls)

\begin{tabular}{|c|c|c|c|}
\hline Sex & Best & General & Dislike \\
\hline Female & 119 & 282 & 95 \\
\hline Proportion (\%) & 24 & 56.9 & 19.1 \\
\hline male & 69 & 323 & 102 \\
\hline proportion (\%) & 14 & 65.4 & 20.6 \\
\hline
\end{tabular}

\subsection{Investigation and analysis of students' sports demand}

According to the survey, the main form of students to participate in physical exercise and is a partner, followed by exercise alone, and participate in school sports associations and the collective activities of the students is relatively small, the number of participating in the gym scanty. It has a relationship with the students' economic strength, the gym is to pay higher fees, for a college student the burden is large, may not have more money to more than used in fitness.

\subsection{The investigation and analysis of the demand of students' sports activities}

Along with the social progress, the demand for sports college students continues to expand, many colleges and universities to introduce a new sports teaching according to the development characteristics of the times, such as outdoor sports, swimming, sports dance, tennis and other projects are more popular among students.

Table 2 student sports fitness project needs statistics

\begin{tabular}{|c|c|c|c|c|}
\hline Sports item & Female $\%$ & Select cumulative sort & male $\%$ & Select cumulative sort \\
\hline Run & 12 & 11 & 12 & 9 \\
\hline aerobics & 2 & 14 & 22 & 5 \\
\hline basketbal & 32 & 1 & 7 & 13 \\
\hline Basketball & 18 & 6 & 0 & 12 \\
\hline volleyball & 14 & 10 & 19 & 6 \\
\hline table tennis & 25 & 3 & 16 & 8 \\
\hline badminton & 19 & 5 & 19 & 6 \\
\hline tennis & 15 & 9 & 25 & 3 \\
\hline Swimming & 21 & 4 & 24 & 14 \\
\hline yoga & 1 & 15 & 5 & 11 \\
\hline wushu & 5 & 13 & 10 & 2 \\
\hline taekwondo & 16 & 8 & 29 & 9 \\
\hline sports dance & 612 & & 11 & 1 \\
\hline skating & 17 & 7 & 30 & 4 \\
\hline outdoor sports & 26 & 2 & & 8 \\
\hline Can be & 15 & & \\
\hline
\end{tabular}

Can be seen from table 2, ranked in the top three of the boys are basketball sports, outdoor sports, table tennis sports; ranked in the top three girls in outdoor sports, sports dance, swimming; boys and girls common sports hobbies have outdoor sports and swimming, the two sports for the school to carry out the situation, conditions are restricted, need facilities investment is large, open the two courses in many universities to the needs of the students a strong sense. In addition, the boys still love ball against the project, these projects can play the advantages of male and female relative. Love dance, yoga class project, these the project does not require confrontation, and can show a female beauty, so more girls love.

\subsection{Investigation and analysis of the time demand and place needs of students' physical exercise}

Learn from the investigation: Boys take part in physical exercise often in the afternoon, the majority, accounting for $42.6 \%$ of the total; girls exercise time for the majority of the evening.the majority of girls exercise time for the evening. Why boys choose exercise in the afternoon is sport for ball games, team cooperation, afternoon free time, weather and field conditions permit; while girls choose to exercise in the evening is because in yoga, aerobics class project, in the interior of the majority. In addition, the boys choose the venue for up to $74.6 \%$, up to $68.8 \%$ girls, students choose to exercise venues in the campus as the leading place, the reason is the venue safe and convenient, free and open, exercise group were age stage, suitable for friends. Choose social venues less. Because social venues are fees, for students, the burden is heavy. It and Square Park, by the facilities and sites so few people choose to exercise. 


\subsection{The investigation and analysis of the students' needs of the physical fitness guidance}

It is important for college students to investigate whether there is a need for physical fitness guidance during the period of school, and most of the students will not need the guidance of body building.After investigation we can see that $43.5 \%$ of boys choose fitness guide, do not need to account for $17.6 \%$; girls, $48 \%$ of people choose to $12 \%$ do not need to choose. Need guidance in physical fitness exercise students, after-school time almost did not participate in sports, including not love sports, no skill, do not understand the knowledge of sports and fitness and other factors. So I hope to have a dedicated sports fitness guidance services, you can always consult, get help.

\subsection{Investigation and analysis of the present situation of sports consumption of students}

Learned from the survey: most of the top students in sports consumption accounted for $68.2 \%$ of clothing, shoes and hats, sports equipment, consumption accounted for $33.6 \%$ of the total, while girls relative to boys sports consumption less than consumption is more than the boys private education costs and expenses in the gym please, this shows that girls tend to separate accept the physical exercise. Sports newspapers and magazines cost relatively little because the development speed of the network has gradually replaced the purchasing books. Sports ticket consumer less, the main reason is the number of the province held a large sports events in the undertaking or less.

\section{Conclusions and recommendations}

\subsection{Conclusions}

At present Jiangxi province college students awareness of physical exercise and fitness is strong, but the actual participation in fitness exercise habits and students is not optimistic; students mental laziness and the temptation of the network is the important factor to hinder the sports activities of colleges and universities in Jiangxi province; not in the field of equipment to meet the fitness needs of a small number of students, no attention in the sports fitness guide service; students demand for sports fitness project is as follows: in the top three of the boys are basketball sports, outdoor sports, table tennis sports; ranked in the top three girls in outdoor sports, sports dance, swimming; sports consumption structure of students gradually rationalized, sports consumption and sports services information consumption is increased.

\subsection{Recommendations}

4.2.1 Increase publicity and fitness training, create a good sports atmosphere

The school should strengthen the sports work investment and policy support, and actively carry out the sports sports activities Scientific Outlook on Development, increase publicity efforts, through the campus radio station, multimedia publicity column publicity of sports fitness knowledge, regularly carry out such as aerobics competition, cross-country, fun games and other activities rich and colorful, full of the school sports atmosphere strong, inspire students to participate in sports exercise enthusiasm, to mobilize more people to participate in sports.

4.2.2 Conform to the characteristics of the development of the times, to increase the emerging class of sports

In order to cater to the characteristics of the development of the times, according to students' physical, psychological needs, sports students love to carry out directly affects the students' interest in sports, such as through the creation of sports dance, swimming, tennis and other courses, let students understand the teaching content of sports diversification in general, exercise conscious use of the hands to guide their own exercise.

4.2.3 Reasonable arrangement of spare time, to develop the habit of physical exercise

College Students' mental laziness has been one of the factors that hinder the exercise, efficient completion of learning tasks, reducing the time to play games online, especially female students to overcome the psychological shy, and with dormitory students cultivate common interests, take the fixed time every day to participate in sports exercise, physical exercise habits, ensure that after entering society, still exercise and drive around the people involved.

4.2.4 Increase the supply of sports facilities and equipment, to meet the needs of the student's diversified fitness 
Strengthen the school sports material conditions of the building, the introduction of various aspects of funding for the construction of sports infrastructure construction, swimming pool, tennis courts, outdoor sports facilities. The school should strengthen the sports fitness service building, the establishment of specialized sports fitness instructor, to compensate for the lack of guiding force. In addition, the school can introduce foreign sports marketing the club, such as small gym, dance classes, proper interference charges, so that the students can afford the fitness project, to provide students with more fitness platform.

\section{Reference}

[1] Liu-min Zhang. Common colleges of Henan Province female college students physical fitness needs of the current situation and countermeasure research [D]. Henan: Henan University, 2009 (3)

[2] Zheng-hong Yin. Investigation of physical quality of college students is [J]. Analysis and Countermeasures of science and Technology Innovation Herald, 2009 (13)

[3] Li-li Ji. [D]. investigation on physical fitness needs the key university students in Beijing. Beijing: Beijing Sport University, 2012 (5) 